\title{
A língua como pátria
}

\begin{abstract}
It is our aim to focus on certain aspects of the complex relationship between language - particularly German - and homeland/identity as seen in the work of a number of Jewish poets and authors. Initially we wish to point out this conflicting relationship in the work of Paul Celan and Rose Ausländer, two Jewish poets born in Romania. The examples of Viktor Klemperer and Ruth Klüger emphasize the complexity of this specific characteristic in the biography/work of German authors of Jewish origin. Elias Canetti, the Nobel Laureate born in Bulgaria, is a literary personality whose biography shows the importance of German culture influence in Eastern Europe at the beginning of the Twentieth Century: Canetti considers himself a German poet who belongs to the German-speaking cultural and literary world.
\end{abstract}

Keywords: Language as identity; German language and the 3. Reich; Jewish authors and their relationship with the German language and culture.

Zusammenfassung: Die Beispiele von Paul Celan und Rose Ausländer zeigen einige dramatische Aspekte des komplexen Verhältnisses zwischen Sprache und Identität, bzw. zwischen der deutschen Sprache im Dritten Reich und der literarischen Identität beider Dichter jüdischer Herkunft. Viktor Klemperer ist das Beispiel eines assimilierten Juden, der stets sein Deutschtum und seine tiefe Zugehörigkeit zu Deutschland und der deutschen Kultur unterstreicht. Ruth Klüger gehört zu einer späteren Generation, die sich eigentlich heimatlos

\footnotetext{
A autora é Professora de literatura alemã da Universidade de São Paulo.
} 
fühlt, aber auch in der deutschen Sprache eine literarische Heimat findet. Canetti, Nobelpreisträger, ein sephardischer Jude, der in Bulgarien geboren ist, wählt für sich als Kosmopolit, als Mensch und Dichter eine Heimat, wo die deutsche Sprache und Kultur die Grenzen bilden.

Stichwörter: Sprache als Identität; Deutsche Sprache and Nationalsozialismus; Jüdische Autoren und ihr Verhältnis zu deutschen Sprache und Kultur.

Palavras-chave: Língua como identidade; Língua alemã e o nacional-socialismo; Autores judeus e sua relação com a língua e a cultura alemãs.

Os tempos sombrios da história alemã, européia e humana do século passado não se limitaram aos anos da época nazista, ao contrário, deixaram uma cicatriz permanente e dolorosa na vida e na obra de escritores de origem judaica e enfatizaram de maneira indelével a dramática tensão entre vítima e algoz. A relação entre língua e pátria que nas regiões em que se falava o alemão revelou-se durante longo tempo natural, óbvia e inquestionavelmente íntima para autores judeus tornou-se a partir de então tudo menos natural, óbvia e inquestionável, trazendo à tona conflitos profundos e incontornáveis e a necessidade premente de justificativas e esclarecimentos para a opção de considerar a língua alemã como pátria literária.

Muitos outros nomes pertencentes a este rol de personalidades judaicas ligadas à cultura alemã vivenciaram com diferentes graus de dramaticidade e intensidade a complexa relação focalizada aqui. Alguns exemplos dessa peculiaridade biográfica demonstram a complexidade extrema da relação entre língua, identidade e pátria e é quase irônico afirmar que justamente esse conflito vivido por autores judeus determinou em especial a poesia alemã contemporânea de forma sensível e intensa. Além dos poetas mencionados a seguir, faço referência igualmente a dois autores que tive o privilégio de traduzir, oferecendo ao público brasileiro a oportunidade de entrar em contato com sua obra. Ao fim, o nome de Elias Canetti, laureado com o Prêmio Nobel de Literatura, exemplifica um outro aspecto extremamente intrigante da relação entre língua alemã e pátria literária. 
O poeta judeu de língua alemã, Paul Celan, nascido em 1920, na cidade romena de Czernovitz, ocupa neste contexto uma posição de particular destaque. A região onde nasceu, a Bucovina, embora cedida à Romênia após a Primeira Grande Guerra, tinha como línguas oficiais o romeno e o alemão; depois disso, até o fim da Segunda Guerra, o romeno instituiu-se como língua oficial, não obstante o alemão continuar sendo largamente falado. $\mathrm{O}$ alemão não apenas se tornara a língua de comunicação literária e cotidiana, foi e continuou sendo a língua materna da maioria da população. Na verdade, Czernovitz foi até 1944 predominantemente uma cidade austríaca, sob influência ainda do antigo império austro-húngaro, depois disso pertenceu à República Soviética da Ucrânia até o fim da União Soviética.

As diferentes influências lingüísticas aí presentes naturalmente deixaram suas marcas no alemão ali falado, contribuindo para o enriquecimento do idioma e conferindo-lhe colorido próprio. Mais do que um terço da população era de origem judaica e, evidentemente, esse fato determinou o cultivo disseminado de antigas tradições judaicas e a existência de uma expressiva intelectualidade, em sua maioria, de língua alemã. Em menor escala, a população judia falava também o ídiche, mas o alemão era sem dúvida a língua da cultura assimilada, utilizada pela maioria dos intelectuais judeus da região.

Não admira, pois, que Celan, depois da destruição desse significativo núcleo eslavo-judaico de cultura e língua alemãs e mesmo após sua libertação do campo de concentração, onde esteve condenado a trabalhos forçados, desse impulso à sua vocação de poeta de língua alemã, com a qual manteve uma relação de atração e repulsa durante toda sua trajetória. A prevalência deste último sentimento, que o fez afirmar ser sua língua materna a língua dos algozes, "a língua dos assassinos de minha mãe"1, certamente foi a causa de profundos conflitos por parte do poeta em relação à sua própria identidade de poeta de língua alemã, levando-o a afirmar com amarga ironia: "Ela, a língua, manteve-se intacta, sim, apesar de tudo [...]

Trata-se de frase famosa de Celan: "Meine Muttersprache ist die Sprache der Mörder meiner Mutter". 
ela percorreu esses acontecimentos. Percorreu-os e pôde vir novamente à tona 'enriquecida' por tudo isso" (Buck 1986: 15). Tal sentimento provocou por seu lado a depuração da língua alemã e uma mudança radical em sua concepção dessa mesma língua, tornando-a, a partir de meios lingüísticos cada vez mais reduzidos, capaz de expressar o indizível, ou seja, as atrocidades provocadas pelos nazistas ao povo judeu em particular e, em geral, aos prisioneiros dos campos de concentração e extermínio, como é o caso do poema talvez mais famoso de Celan, a Fuga da Morte (Todesfuge), escrito em 1945.

Utilizando-se de recursos lingüísticos e estilísticos relativamente simples, Celan concebe nesse poema um jogo artístico elaborado, utilizandose de material poético resgatado à tradição lírica que, através da técnica da montagem, torna-se um monumento solene em memória das vítimas do Holocausto, uma lembrança da bestialidade altamente refinada do assassinato em massa. Pondo de lado modelos de expressão convencionais da lírica, Celan abdica da pieguice, de sentimentalismos e ornamentações, em prol do sentimento. O resultado dessa tentativa de evitar conscientemente, através de metáforas recorrentes da tradição literária, a mera bagatelização e a poetização dos horrores do extermínio nazista, pode ser considerado uma alternativa para a afirmação famosa de Adorno, segundo a qual seria bárbaro escrever poemas depois de Auschwitz, correndo-se o risco de recair na simples reprodução da banalidade do mal. A obra de Celan, que no decorrer dos anos subseqüentes à Fuga da Morte se torna cada vez mais hermética, corrobora a reflexão a respeito do conflito do poeta entre língua e identidade, podendo mesmo tal conflito ter sido um dos motivos que o levaram ao suicídio em 1970.

Outro nome a ser lembrado é o de Rose Ausländer (1901-1988), uma judia também nascida em Czernovitz, porém muito menos conhecida que Celan. A própria poeta esclarece sua condição e suas palavras complementam a afirmação anterior de Celan: "Por que escrevo? Talvez porque tenha vindo ao mundo em Czernovitz, porque o mundo veio a mim em Czernovitz. Aquela paisagem singular. As pessoas singulares. Contos de fadas e mitos pairavam no ar, nós os respirávamos. Czernovitz, com suas quatro línguas, era uma cidade das musas que abrigava muitos artistas, poetas, amantes das artes e da literatura. (...).” (apud WitTe 2002: 2) 
Também Rose Ausländer demonstra que em seus poemas o conceito de língua não mais está aliado a uma identidade nacional, e sim apenas associado à palavra ou às palavras que a constituem. Trata-se de um território próprio em cujos limites a poesia pode se expressar, transformar-se, proporcionando à poeta a descoberta de sua voz lírica e o encontro de si mesma. O abrigo nesse refúgio poético resgata a integridade do eu-lírico, entendida sob vários ângulos: integridade física, psicológica, poética, geográfica. A pátria lingüística é a instância responsável por um sentimento de segurança e aconchego, que reverte para Ausländer o processo da perda da identidade. $\mathrm{O}$ reencontro do eu ocorre a despeito da permanente sensação de não-pertencimento, de viver eternamente entre mundos, entre a Europa e a América, incapaz de fixar-se em lugar algum.

O retorno à língua alemã e tudo que está contido nesse processo foi, obviamente, complexo. Aí, evidentemente, insere-se a reconquista da identidade, entenda-se tanto a identidade pessoal quanto a poética, roubadas pelo regime nazista. As imagens poéticas da antiga pátria, determinantes de sua identidade, permanecem intactas: é a elas que deve sua identidade poética, embora o trauma da pátria perdida e, por conseqüência, da identidade pessoal perdida, nunca fosse totalmente superado, assim como nunca foram esquecidas as lembranças dolorosas dos anos sombrios, a exemplo de Celan. Perdida a pátria para o eu-indivíduo, o eu-lírico procura refúgio na língua materna que adquire então um novo significado: se a pátria, "Vaterland", perde seu significado, a língua, a "mátria", "Mutterland", ao contrário passa a ser seu mundo poético, seu único mundo.

Rose Ausländer nunca se pronunciou especificamente a respeito da afirmação polêmica de Adorno acerca da impossibilidade de se escrever poesia depois de Auschwitz. No entanto, a concepção de "MutterlandWort", "mátria-palavra", poderia constituir-se numa espécie de resposta de Ausländer para a questão. A memória, embora intacta, não poderia mais ser resgatada, pois a língua, maculada pela barbárie, vê-se condenada ao silêncio, única reação diante das atrocidades cometidas. No entanto, é preciso evitar que a barbárie seja esquecida, é imprescindível prestar testemunho em nome de si mesma e em homenagem às vítimas. No novo refúgio poético, torna-se possível para ela fazer isso. Aí consegue preservar-se e preservar a poesia, aí não há limites, a liberdade é total, deixando entrever 
que para Rose Ausländer, num misto de fé e esperança, a poesia segue sendo possível.

Os exemplos precedentes equivalem-se na rejeição da língua alemã como pátria lingüística e a dramática, pois relutante, aceitação da mesma como instrumento do único meio de expressão possível para a voz lírica.

A figura de Viktor Klemperer (1881-1960) serve como contraponto e revela um outro aspecto do tema aqui exposto. Klemperer foi professor universitário e um romanista conceituado ligado à Universidade de Dresden até a ascensão de Hitler ao poder, e autor de uma autobiografia de grande impacto e sucesso, publicada postumamente a partir de 1990 (KLEMPERER 1999).

Filho de um rabino, Victor Klemperer nasceu em Landsberg/Warthe em 1881 e converteu-se ao protestantismo em sua juventude, como resposta à sua assimilação e à constante reiteração de sua condição de alemão "acima de tudo". Nos primeiros anos do nacional-socialismo, o Victor Klemperer, por ser judeu, perdeu sua cátedra e aos poucos todos seus direitos de cidadão, alemão, conforme pensava. A princípio, imaginava o nacional-socialismo uma loucura passageira, opinião que logo se transformou à medida que o regime se brutalizava cada vez mais. Ao contrário de amigos e parentes, suas tentativas de emigrar nunca foram seriamente programadas. Klemperer acabou por permanecer na Alemanha e sobreviveu graças a circunstâncias particularmente dramáticas, relatadas com pormenores em seu diário.

Nele Klemperer reitera veementemente sua condição de alemão e sua profunda ligação com a Alemanha, cuja língua e a cultura seriam para ele a razão e a essência mesma de sua existência, lutando com todas as forças para mantê-las a despeito de tudo. Em suas minuciosas anotações diárias, nota-se o permanente jogo entre a subjetividade e a objetividade. Ressalte-se nos Diários a constante tentativa de não permitir que emoções tomem conta da mente racional própria do intelectual e, por conseguinte, o temor que tais emoções obstruam o distanciamento crítico necessário à objetividade. Klemperer não poupa ninguém em suas anotações, tampouco a si mesmo, tornando a sua "alemanidade" ("Deutschtum”), defendida até o fim, objeto de profundas e controvertidas reflexões, assim como a crença tragicamente desmentida da mais frutífera simbiose existente na Alemanha entre judeus e alemães. 
Nesse contexto, vale mencionar também Ruth Klüger (1931-), uma germanista radicada nos Estados Unidos, autora de autobiografia recém publicada no Brasil, que revelou no lançamento em São Paulo da tradução de seu livro o fato de não ter pátria, tendo se perdido para ela o sentimento de pertencimento a um lugar natal, sua pátria de origem, a Áustria. A obra em questão, Paisagens da Memória - Autobiografia de uma sobrevivente do Holocausto (KLÜGER 2005), foi primeiramente escrita em alemão, em Göttingen, cidade alemã que adotou como uma espécie de refúgio apaziguador da relação entre língua e identidade, tendo sido transposta em seguida para o inglês, seu segundo meio de expressão.

Totalmente diferente revela-se a relação entre língua e pátria na vida e obra de Elias Canetti, um judeu sefardita, nascido em 1905, na Bulgária, um país, portanto, fora dos limites do império austro-húngaro. Canetti aprendeu o idioma alemão só aos oito anos de idade, depois do ladino, do búlgaro, do inglês e do francês. A partir de então, apesar da aquisição sofrida, mas perseverante da língua alemã, manteve-se fiel a ela por toda sua vida, considerando-a sua verdadeira língua materna, enfatizando sempre sua condição de "poeta alemão" desde seu primeiro romance, Auto-de-Fé (Die Blendung), finalizado em 1931, em Viena, sua pátria de adoção.

No exílio na Inglaterra, onde se refugiou em 1938, escapando aos nazistas que acabavam de anexar a Áustria ao Reich, declara: “... sempre escrevi em alemão e assim prosseguirei. $O$ alemão tornara-se para mim importante demais quando cheguei à Inglaterra para que algo pudesse mudar nesse sentido. O orgulho também deve ter representado um papel significante nesse caso. Não queria permitir que ninguém - e muito menos Hitler - determinasse em que língua devo escrever ou não. Meus antepassados tiveram que abandonar a Espanha em 1492 e levaram a sua língua para a Turquia, onde se estabeleceram. Este espanhol foi mantido puro por eles durante 400 anos em sua nova pátria e também foi minha língua materna. Aprendi alemão aos oito anos e fui amadurecendo dentro desta língua. Aos 33 tive que abandonar Viena e levei comigo o alemão, da mesma forma que eles tinham levado o seu espanhol. Talvez eu seja a única personalidade literária para a qual as línguas dos dois grandes banimentos da História se concentram desta maneira. Uma constelação assim curiosa não deve ser perturbada. É mais sensato deixá-la vir à tona simplesmente. Algumas ve- 
zes sinto-me um poeta espanhol de língua alemã. Quando leio os antigos espanhóis, como a Celestina ou os Sueños de Quevedo, creio expressar-me através deles. Ninguém sabe quem realmente é. Dá-me forças saber apenas isto" (CANETTI 1972:103).

Ao fazer esta afirmação em uma entrevista de 1965, Elias Canetti não alcançara ainda uma repercussão significativa nos países de língua alemã, compatível com sua estatura literária. A não ser um número restrito de intelectuais e estudiosos, ninguém realmente sabia quem era Canetti, uma figura singular que ocupa uma posição singular no âmbito da literatura de língua alemã. Quando da outorga do Prêmio Nobel de Literatura em 1981, a notícia praticamente só teve repercussão junto a germanistas e aos meios de comunicação. A mídia alemã, no entanto, não expressou em nenhum momento o sentimento de orgulho nacional, típico para uma notícia desse porte, e sim, apenas, surpresa e uma indagação.

A surpresa deveu-se talvez ao fato de que a Academia Sueca conferira a um escritor judeu búlgaro de língua alemã o maior prêmio literário internacional, em detrimento de outros autores alemães, na época, constantemente presentes nas listas dos "premiáveis", como Günter Grass, por exemplo. Por sua vez, a indagação sobre afinal quem era o autor laureado revela um fenômeno peculiar: a repercussão restrita por ocasião do Prêmio Nobel seria então, de fato, surpreendente, se não constituísse um sintoma recepcional característico para as dificuldades de definir a posição literária de Canetti no contexto da literatura de língua alemã e de estabelecer sua importância nesse mesmo contexto, do qual, na verdade, sempre se manteve longe na maior parte de sua vida. A recepção singular de Canetti não só tem a ver com a singularidade de sua obra, de caráter marcadamente extemporâneo, já que nenhuma definição parece ajustar-se exatamente a ela. Esta característica recepcional deve-se igualmente a particularidades de sua biografia, a uma espécie de abstinência literária forçada ou mesmo à relutância consciente em publicar sua obra.

Assim, explica-se o fato de ter sido apresentado à Academia Sueca como "poeta exilado e cosmopolita, cuja pátria é a língua alemã”. Curiosamente, o escritor austríaco Hermann Broch já o definira desta maneira, em 1933, por ocasião de uma das raras leituras do romance Auto-de-Fé, concluído dois anos antes e ainda não publicado naquela ocasião. Broch, da mes- 
ma forma, enfatizara naquela data a condição de "poeta alemão" do jovem escritor, não obstante a sua origem judaico-sefardita e sua naturalidade búlgara.

Neste sentido, não surpreende o fato de Canetti, em seu discurso de agradecimento à Academia Sueca, prestar uma homenagem comovente às três Stadtgottheiten, às três cidades-deusas, divindades, que marcaram sua trajetória: Viena, Londres e Zurique. Ao mesmo tempo, homenageia quatro personalidades a quem atribui a sua presença ali naquele momento e cuja influência declara indiscutível e marcante para sua produção literária: Karl Kraus, Franz Kafka, Hermann Broch e Robert Musil. Quatro nomes significativos da literatura em língua alemã, três deles compartilham da mesma origem judaica de Canetti e todos do mesmo caminho solitário percorrido por ele e de sua singular recepção.

Através da referência a estes representantes da literatura de língua alemã, fica claro quais são as raízes literárias de Canetti e o contexto lingüístico e cultural em que se insere. Os reflexos dessa cultura multifacetada e rica, uma constante e inigualável fonte de estímulo, faziam-se sentir muito além dos limites do citado império, atingindo sua influência para além dos Bálcãs. A abrangência desta zona de ressonâncias culturais revela-se, por exemplo, na importância que a pequena cidade de Rustschuk, ou Ruse, às margens do Danúbio, extremo norte da Bulgária, adquiriu por volta do começo do século XX. Essa localidade, onde Canetti nasceu em 1905, representava o último porto fluvial que separava o "Oriente" propriamente dito, do resto da "Europa". E a "Europa" que magnetizava culturalmente a elite dessa cidadezinha do "Oriente" era sinônimo do império austro-húngaro e de sua língua oficial, o alemão, símbolo de europeização, assimilação e aculturação para os povos de outras origens, principalmente para os judeus que ali habitavam, já desvinculados de sua tradição lingüística, religiosa e cultural mais rígida e fechada. Para estes judeus, o alemão representava uma ascensão cultural, adquirindo o significado de uma nova pátria lingüística.

O alemão, também para a família de Canetti, viria a tornar-se, ao lado do ladino, estranho e exótico, a verdadeira língua materna, a misteriosa Zaubersprache em que os pais se comunicavam entre si, a "língua mágica", "implantada tardiamente e sob verdadeira tortura", conforme declara no primeiro volume de sua autobiografia, A Lingua Absolvida. 
Toda a formação escolar, profissional, cultural e literária de Canetti dar-se-ia no contexto de língua alemã, com passagens marcantes por Viena, Zurique e Frankfurt e, novamente, Viena, abandonada relutantemente após a Noite dos Cristais, em 9 de novembro de 1938. A partir de então, Canetti torna-se definitivamente cidadão do mundo, com domićlío em Londres, a princípio, depois nessa cidade e em Zurique, onde veio a falecer em agosto de 1994, aos 89 anos.

Canetti viveu, portanto, sem contar os anos finais, grande parte de sua vida desde o exílio num contexto lingüístico estranho à língua alemã, na Inglaterra, cuja língua dominava tão fluentemente quanto o alemão. No entanto, Canetti manteve-se fiel à sua identidade de poeta alemão e terminada a Segunda Guerra Mundial jamais concordou em aceitar a hospitalidade sempre reiterada de retornar à Viena, sua pátria de adoção, onde poderia ter ocupado a posição de poeta oficial, vaga devido à emigração forçada de tantos autores judeus ou não que optaram por permanecer nos países que os abrigaram e ali faleceram. Canetti, no entanto, jamais abdicou tanto de sua fidelidade à Viena, sempre repetida em sua obra, quanto de sua simbiótica e frutífera relação com a língua alemã, mesmo no exílio, o que não é surpreendente, pois Canetti, de certa forma, sempre experimentou o exílio por força de sua origem e destino. Igualmente, pouco surpreende a recusa de Canetti, quando em meados dos anos sessenta, os escritores alemães Günter Grass e Peter Weiss lhe propuseram, em nome da Academia de Letras de Berlim, que ele se associasse a seus membros e para tal o convidaram a vir a Berlim. Canetti declinou o convite, jamais abrindo mão, portanto, de sua posição periférica no que concerne ao movimento literário de língua alemã.

Conforme mencionado anteriormente, apenas em 1935 Canetti publica sua primeira obra, seu único romance, escrito no início dos anos trinta: Auto-de-Fé. Excetuando-se algumas sessões de leitura a amigos, o romance mal obteve eco na Áustria. Vale mencionar que a situação política da Alemanha - com seus reflexos na Áustria - impediu que o romance atingisse um público maior. A queima de livros de escritores alemães de origem judaica ou de coloração política contrária à oficial ocorrera dois anos antes apenas, em 1933, e a produção literária alemã mais significativa reduziu-se nesses anos a obras publicadas no exílio, restritas a um pequeno público. No entanto, apesar destes fatos - ou até mesmo devido a eles - a obra 
inicial de Canetti desapareceu do circuito alemão por longos anos. O romance de Canetti, a julgar a época em que foi escrito - antes de 1933, ano da tomada do poder por Hitler, demonstrou ser uma das obras mais clarividentes da barbárie prestes a se desencadear na Alemanha, focalizando, como uma antecipação sombria da História - e da própria queima de livros citada anteriormente -, as tendências e a dinâmica destrutiva do totalitarismo, provocando mesmo, anos mais tarde, o espanto de seu próprio autor por sua premonição. Neste sentido, Canetti afirma em um aforismo de 1946: "O que você criou cheio de horror, demonstra ser mais tarde uma simples verdade" (CANETTI 1973: 86).

Grande parte da obra de Canetti, publicada até hoje, é oriunda da primeira fase da produção literária do autor. As obras publicadas nos anos setenta e oitenta, os três volumes de sua autobiografia que abrangem os anos de 1905, seu nascimento, até 1937, praticamente o último passado em Viena, os ensaios, a narrativa de viagem, Die Stimmen von Marrakesch (As Vozes de Marrakech), e os volumes de aforismos, retomam, de certa forma, temas que caracterizam a "fase vienense" de Canetti. Numa referência a esta afirmação de que tudo que Canetti escreveu teve sua origem em Viena, pode-se mencionar a constatação de Canetti no primeiro volume de sua autobiografia, $A$ Lingua Absolvida, segundo a qual tudo que vivenciara em sua longa existência na verdade já tinha ocorrido um dia em Rutschuk, durante sua infância.

Canetti veio a conquistar internacionalmente um público fiel. O interesse despertado por sua obra decorre, por certo, do testemunho arguto, sincero e sensível do autor relativo a uma época extremamente profícua, caracterizada pelo surgimento de obras excepcionais nas mais diversas áreas da produção intelectual, cujo traço comum é o fascínio do novo num mundo prestes a esfacelar-se. Os grandes movimentos políticos e sociais do século passado foram vivenciados por Canetti e estão presentes em sua obra como advertência daquilo que a humanidade presenciou e continua presenciando. Os mais relevantes acontecimentos culturais e literários, por sua vez, também nela estão presentes, caracterizados pela marca inconfundível da modernidade.

Não obstante a recepção de Canetti nos países de língua alemã ter sido um processo longo e entremeado de obstáculos, sem dúvida, porém, Canetti veio a desempenhar um papel significativo também na vida literária 
alemã. Apesar desse sucesso tardio, Canetti permaneceu até sua morte perseverantemente solitário, jamais cogitando de abrir mão de sua posição marginal. Seu exílio, voluntário até sua morte, pode ser entendido como asilo, como forma de vida. É nesta posição que Canetti pagou seu tributo à língua alemã, sua verdadeira pátria lingüística. Nos últimos anos da guerra, declarou: "A língua de meu espírito permanecerá sendo a alemã - e justamente por que sou judeu. O que sobrará daquele país devastado sob todos os pontos de vista quero preservar em mim como judeu. O seu destino também é o meu; mas trago comigo um fator humano a mais. Quero restituir à sua língua o que lhe devo" (CANETTI 1973: 62). Em outro aforismo, de 1945, Canetti retoma o mesmo pensamento: "Hoje com a Alemanha em ruínas, tudo mudou ... . As pessoas logo irão procurar por sua língua, que lhes foi roubada e deturpada. Quem a manteve sempre pura nos anos da maior loucura terá que cedê-la agora... e devolvê-la (aos alemães) com amor e com agradecimento, com juros e mais juros" (CANETTI 1973: 75).

Tais citações revelam a sua relação singular com as palavras alemãs, sobretudo sua preocupação com a língua alemã no exílio. Sob esta constelação histórica aguça-se igualmente a compreensão, agora mais profunda, de sua responsabilidade literária, de seu "ofício de poeta" de língua alemã, judeu sefardita, nascido na Bulgária, cidadão do mundo, cuja obra está também fortemente impregnada pela tradição milenar de seus ancestrais.

\section{Referências bibliográficas}

CAnettr, Elias. “Gespräch mit Horst Bienek". In: CAnetTi, E. Die gespaltene Zukunft. München, Hanser 1972.

Canetti, Elias. Die Provinz des Menschen. Aufzeichnungen 1942-1972. München, Hanser 1973.

KLeMPERER, Viktor. Os Diários de Viktor Klemperer 1933-1945 (Ich will Zeugnis ablegen bis zum letzten. Tagebücher 1933-1945). Tradução de Irene Aron. São Paulo, Cia. das Letras 1999.

KLÜGER, Ruth. Paisagens da memória. Autobiografia de uma sobrevivente do Holocausto. (weiter leben. Eine Jugend). Tradução de Irene Aron. São Paulo, Editora 342005. 
Barnouw, Dagmar. Elias Canetti. Stuttgart, Metzler 1979.

Bischoff, Alfons M. Elias Canetti - Stationen zu seinem Werk. Bern, Peter Lang 1973.

Bollacher, Martin. “'Chaos' und 'Verwandlung' - Bemerkungen zu Canettis Poetik des Widerstands”. In: Euphorion, vol. 73 1979, 169-185.

Bollacher, Martin. "Vom Gewissen der Worte. Elias Canetti und die Verantwortung des Dichters im Exil”. In: GrimM, G. E./ BAYERDÖrfFER, H. P. (ed.), Im Zeichen Hiobs, Königstein/ Ts., Athenäum 1985, 326-337.

Braun, Helmut (Ed.). Rose Ausländer - Materialien zu Leben und Werk. Fischer, Frankfurt 1991.

Buck, Theo. "Lyrik nach Auschwitz - Zu Paul Celans 'Todesfuge". In: Akten des Internationalen Paul Celan-Colloquiums, Haifa 1986. In: Chaim Shoham / Bernd Witte (Ed.), Datum und Zitat bei Paul Celan. Bern, Peter Lang 1986. 11-41.

DurZaK, Manfred (Ed.). Zu Elias Canetti, Stuttgart, Klett 1983.

GÖPFERT, Herbert G. (Ed.). Canetti lesen - Erfahrungen mit seinen Büchern. München, Hanser 1975.

Kaszinski, S. H. (Ed.). Die Lesbarkeit der Welt. Poznán, Drukarnia Uniwersytet Adama Mickiewicza 1984.

PIEL, E. Elias Canetti. München, Beck/ edition text + kritik 1984.

VÁrIos. Hüter der Verwandlung - Beiträge zum Werk von Elias Canetti. Frankfurt a.M., Fischer 1985.

Witte, Bernd, "Rose Ausländer". Artikel in: H. L. Arnold (Ed.) Kritisches Lexikon der Gegenwartsliteratur. München: Ed. text + kritik 2002. (CD-Rom) 